\title{
La panorámica de la guerra civil española en el cómic
}

Reseña de: MatLy, M., El cómic sobre la guerra civil, Madrid, Cátedra, 2018

\author{
Jacobo Hernando Morejón ${ }^{1}$
}

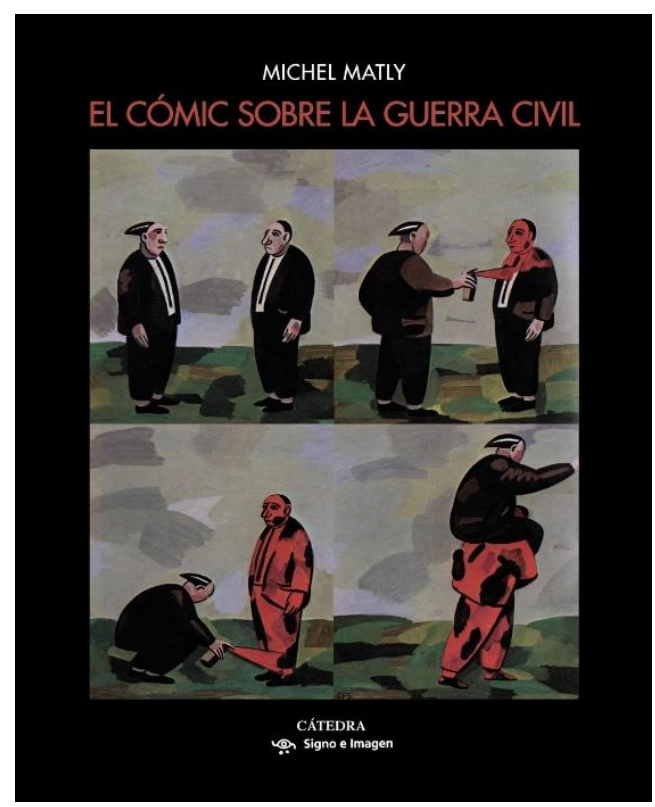

Uno de los hechos más trascendentales para el devenir de la historia de España en el siglo XX fue la guerra civil española (1936-1939) que provocó el final de la segunda república y el comienzo de la dictadura del general Francisco Franco. Un hecho tan importante posee una sombra tan alargada como para que, todavía hoy, siga estando en el candelero de las noticias de actualidad; tanto como para influenciar una densa historiografía, filmografía y literatura. Pero, de algún modo, su impronta sobre los cómics no ha empezado a cobrar relevancia, tanto para público como para editores y autores en nuestro país, hasta hace poco. Con todo, lo que el cómic, en su forma de novela gráfica, vive con esta temática es propio de una auténtica edad dorada de atención y publicaciones. Por tanto, ante un panorama desconocido incluso para lectores veteranos, la pregunta que debía hacerse es ¿Cómo se ha representado el conflicto en las viñetas?

El investigador Michel Matly (Dompierre-sur-Bresbe, 1952), que ya codirigiera el congreso sobre Guerra civil española y cómic (Angoûleme, 2016), firma el presente libro para contestar a esta pregunta. Teniendo su origen en la tesis doctoral defendida en 2016, el fruto de su trabajo es editado ahora en un tomo que explora el impacto como temática que la guerra civil ha tenido en la producción de historietas, no solo en España, sino en todo el mundo.

1 Universidad de Málaga. 
Además, el material de su análisis no se queda únicamente en las novelas gráficas que más atención han captado, sino que recopila cualquier tipo de referencia, en un trabajo de búsqueda titánico si consideramos el difícil acceso que a algunos materiales se tiene o a la pérdida de otros muchos.

La publicación de este libro no podía haber ocurrido en un contexto más propicio. La historieta histórica está viviendo un gran momento y la temática sobre el siglo XX español, con la guerra civil, el exilio y el franquismo, encabeza el motivo de este auge reciente. Se producen aportaciones científicas tanto en congresos como en revistas (únicamente en 2018 ya han salido dos libros referidos a la guerra civil y a la memoria histórica); un filón motivado también por cierto interés docente por poder acercar estos episodios de nuestra historia a sus alumnos.

La portada es simbólicamente perfecta con Guerra civil de Rábago García. Será profusamente comentada al final del contenido. Una vez abierto el libro, vamos a encontrar un total de 18 capítulos más introducción y un epílogo, estructurados en un discurso fácil de comprender. Temáticamente se divide en dos mitades y el autor separa las partes con bastante soltura y pragmatismo.

La primera mitad cuenta con una introducción histórica, que repasa brevemente lo más importante del contexto de las publicaciones referidas y luego, máxime, vemos según la zona geográfica de publicación; en primer lugar, nos detenemos en el caso español para, posteriormente, observar lo que ocurría en el extranjero.

Entre otras cualidades, esta división permite saber cuál podía ser el grado de aceptación del franquismo; en Argentina, la historieta reconoce como el bando «bueno» a los sublevados, mientras que en México o Chile se apoya la causa republicana.

Este discurso diacrónico, pues, no puede empezar de otra manera que desde el propio inicio de la contienda. El reflejo del conflicto analiza la expresión acerca de la guerra desde distintos autores, aunque sin caer en parcialidades, observando, empero, que estos van a decantarse mayoritariamente por una visión pro república.

Para orientar mejor esta disposición de elementos, la narración distingue dos periodos de acuerdo a un punto cronológico concreto: la muerte de Franco. Antes, se estudian los casos de manera conjunta, aunque separados geográficamente llegado el caso, y después del deceso la cantidad de obras 
aumenta y deben dedicarse capítulos individuales, de los cuales el caso de la industria española es el más extenso. Más adelante se trata el caso francés, dejando otros países mezclados según afiliaciones geográficas. No resulta raro entender esta disposición del análisis; después de todo, los países que no tuvieron participación directa o que no recuerdan haberla tenido no tienen apenas menciones, como Irlanda o Polonia, sin ser sorprendente que los superhéroes estadounidenses lleguen a figurar en el conflicto.

La segunda parte del libro va a revisar específicamente ciertos temas a los que dedica a cada uno un capítulo. El primero, la violencia ejercida contra la población civil, se muestra como una justificación para el bando franquista para desplegar su propia violencia y empezar el conflicto durante la guerra y la dictadura.

Hasta los años 2010 el cómic español no empezará a abordar este tema de manera frecuente frente a la crudeza y familiaridad vista en Argentina. Ya tras la muerte de Franco, la violencia es vista como un hecho deleznable, con la republicana documentada por la dictadura mientras que la franquista es meramente genérica; ambas partes van a recibir críticas por parte de los cómics de la democracia pero, por ser la que ganó, la represión de los nacionales continuará mucho después del fin de la propia guerra. Gracias a estos cómics podemos ver que las heridas no se cerraron y que los traumas son transmitidos de padres a hijos. Es especialmente interesante el caso de la violencia aplicada sobre las mujeres en todo su horror, como el caso de Moros.

En relación a la violencia pero en capítulo aparte, a la iglesia católica se la retrata como una víctima del anticlericalismo republicano y de las facciones que durante el conflicto van a intervenir. Sin embargo, no es hasta Martillo de herejes (2006) donde el homicidio de hombres de la iglesia tiene lugar dentro de las historietas españolas; hasta entonces, los ataques eran representados mediante la destrucción de bienes pero de manera genérica, mediante iglesias en llamas decorando el fondo de las viñetas.

Es constante la asociación de colaboracionismo del clero con las fuerzas nacionales, aunque hay excepciones y hasta ejemplos de apoyo al legítimo gobierno. Esta violencia, asociada inherentemente al advenimiento de la república que, junto al pueblo que se rebela contra esta institución religiosa, es recordada a menudo e instrumentalizada para tapar las injustificables acciones de violencia contra civiles.

El capítulo dedicado a la cárcel y al exilio nos presenta un panorama interesante, dado que hasta los años 70 no pueden localizarse las primeras 
referencias al exilio. La comparativa entre el desequilibrio existente entre publicaciones dedicadas a una u otra circunstancia es, de igual manera, muy razonada. La cárcel es otro itinerario distinto, menos traumático y cargado de dramatismo que el exilio. Los fusilamientos de los prisioneros incluyen el componente de responsabilidad de un bando u otro. La prisión republicana es la primera en ser ilustrada y es, como la de su adversario, una antecámara antes del paredón; la franquista es igual pero hay una fuerte sensación de arbitrariedad en los responsables por decidir quién vive y a quién se le da el paseíllo.

El exilio es, sin embargo, objeto de descanso y recuperación para el republicano fugitivo de su patria, pero también supone una crítica al trato dispensado por Francia en forma de campos de concentración y trabajos forzados. La intensidad de los maltratos del país de acogida varía, siendo mostrado en ocasiones el rechazo de la propia población civil gala. El exilio latinoamericano va a recaer principalmente en la labor de los historietistas locales.

Finalmente, en el último capítulo, el autor entra en la revisión de los símbolos utilizados. Matly da cuenta de lo fácil que es distinguir los del bando vencedor y a diversos grupos que conformaban la resistencia republicana sin que esté presente la misma república. El autor lo resume perfectamente con su pregunta: ¿Dónde está, pues, la república? El razonamiento que hace acerca de la no presencia de la bandera tricolor no va para nada desencaminado al relacionarlo con la ausencia en la cartelería de guerra de la zona republicana, dado que, como también apunta, la guerra civil en cómic es una rerepresentación, la imagen gráfica de la simbología que tenemos muchos de nosotros proviene de la propaganda visual del conflicto y, en esta, dicha bandera carece de la representatividad que se le debería presuponer frente a la rojigualda.

De manera adicional, se señala una verdad acerca de los tebeos de la guerra: el soldado franquista brilla por su ausencia, más no sus superiores, y en el campo republicano no hay líderes, físicamente presentes, sino militantes de base. Esto podría achacarse a los argumentos teorizados por Matly: la república desaparece en el momento del alzamiento, pero también, en mi modesta opinión, si lo ponemos en un contexto mayor del devenir de la historieta histórica, cuanto más nos acercamos al presente, los argumentos de los cómics así como sus personajes pasan de versar sobre historias político-militares, de grandes hechos y personalidades, a ser historietas con el hombre común, el pueblo, como origen de las mismas. 
En conclusión, estamos ante una obra monumental, básica para cualquier investigador o lector que desee ahondar en nuestro pasado cercano a través del cómic. Lo que primero encontrará será una buena base de referencias a títulos, la evolución de las corrientes de opinión sobre la guerra y un sólido punto de partida bibliográfico desde el que desarrollar futuras investigaciones propias.

Michel Matly firma un clásico de la historiografía adscrita al cómic; un trabajo cuya vigencia puede ser proyectada fácilmente numerosos años por delante y un referente mundial en cuanto a su especialización. Gracias a su trabajo, el camino, y la ausencia de bibliografía específica habitual, es menos oscuro y solitario. 